\title{
Morphological Analysis Of Obstructive Sleep Apnoea Patients Using Computed Tomography
}

\author{
Sidika Deniz Yalim MD, Fatma Feride Gorgulu MD² \\ 1 Department of Otorhinolaryngology, Adana City Training and Research Hospital, Adana, Turkey - ORCID ID: 0000-0001-7833-8421 \\ 2 Department of Radiology, Adana City Training and Research Hospital, Adana, Turkey - ORCID ID: 0000-0001-5830-0637
}

\begin{abstract}
Objective: The aim of the the study was to compare CT-obtained measures related to the cross-sectional area of the airway at various points (nasal valve, mid-nasal cavity, choanal, retro-lingual and retro-uvulal) in cases of obstructive sleep apnoea (OSA) with their values in normal controls. Such abnormal values may act as markers of risk for OSA.
\end{abstract}

Methods: CT (computerised tomographic) imaging from 27 cases of OSA attending the Otorhinolaryngology Dept. of the Adana City Training and Research Hospital were evaluated retrospectively, alongside 9 normal controls.
Results: the means of the nasal valve and choanal cross sectional areas differed from the normal control means at the level of statistical significance $(p=0.019$ and $p=0.012$, respectively).

Conclusion: The authors hypothesize that the area of the nasal valve and the choanae have a bearing on the likelihood of developing OSA, but state that further research involving larger populations is needed to draw firm conclusions.

Key words: morphologic analysis, obstructive sleep apnea, computed tomography.

\section{Introduction}

Obstructive sleep apnoea (OSA) has a prevalence of no less than $2-4 \%$ of adults and is therefore frequently seen (1). $3.1-7.5 \%$ of men, and $2.1-4.5 \%$ of women, have the disorder, according to a number of epidemiological studies (2-8). Respiration ceases periodically whilst the sufferer is sleeping, leading to the signs and symptoms of the disorder and accounting for its sequelae, e.g. a heightened risk profile for circulatory disease. There are associations between OSA and numerous other conditions, such as high blood pressure, diabetes mellitus, obesity, gastroesophageal reflux, impotence, depression, and elevated levels of cardiovascular and cerebrovascular morbidity and mortality (9). Thus, suspecting and diagnosing OSA is a key clinical imperative.
Cephalometry using lateral X-ray has been the focus of a number of studies that looked for correlations between cephalometric features and OSA. It is unclear, however, to what extent such measurements can be relied on in diagnosis in ordinary conditions, since the airway is a three-dimensional space that can only be visualised adequately using different techniques, such as CT or MRI (magnetic resonance imaging). CT using a multislice technique does, on the other hand, have a beneficial profile in terms of reproducibility of measurement and reliability, aiding standardisation (10).

The nasal cavity is at its most constricted in the area of the nasal valve. Indeed, this constriction accounts for 50\% of the total resistance to flow within the airway as a whole
Correspondence: Sidika Deniz Yalim

Dr.Mithat Ozsan Blv Kısla Mh 4522 Sk No 101030 Yuregir, Adana, Turkey

Telephone: +9032245590000

e-mail: denizmicozkadioglu@yahoo.com

Received: January 20, 2019; Accepted: February 16, 2019
Online available at www.entupdates.org

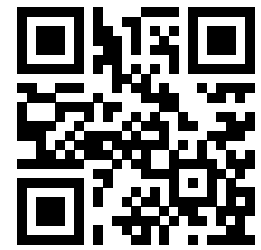


(11). For inspired air, the nasal valve is the first obstruction to pass within the nasal cavity. The pharynx communicates with the cavity of the nose via the choanae. The pharynx is envisioned as possessing two zones with divergent functions - the area behind the velum (retropalatal locus) and that behind the tongue where it is angulated vertically (retropalatal locus) (12).

The present study aims to evaluate cross sectional measurements (nasal valve area, middle nasal passage area, choanal area, retrouvulal and the retrolingual areas) in patients with obstructive sleep apnoea using CT measurements to reveal any significant differences in patients with OSA from normal controls, which may indicate a susceptibility to OSA.

\section{Materials And Methods}

CT (computerised tomographic) imaging from 27 cases of OSA attending the Otorhinolaryngology Dept. of the Adana City Training and Research Hospital were evaluated retrospectively, alongside 9 normal controls. All those involved gave informed consent to participate. The study gained ethical approval from the Institutional Ethics Committee and followed the principles laid out in the Declaration of Helsinki.

All the measurements were taken using Phillips Ingenuity Core 128 Multislice computed tomography. The field measurements were performed using the auto contour measurement tool under the CT viewer pane after the measurable cross-sectional area had been displayed. The cross sectional measurements of the nasal valve areas (right and left) (Figure 1), the middle nasal passage areas (right and left) (Figure 2), the choanal area (Figure 3), the retrouvulal area (Figure 4) and the retrolingual area (Figure 5) were calculated. These values were calculated manually by a radiologist of nineteen years' experience, with blinding to other data regarding OSA status of the individual.

\section{Statistical analysis}

The SPSS Statistics 21.0 package application was used to perform all the statistical calculations reported here. The Shapiro-Wilk test was used to check conformity of the data with a normal distribution. The difference between the means of the control and cases groups was calculated using Student's $t$ test. The mean, standard deviation, minima and maxima were the descriptive statistics used. Logistic regression was employed for calculating how the variables translated into clinical risk. Odds ratios were used and 95\% confidence intervals applied. In all cases, statistical significance was defined as a $\mathrm{p}$ value less than 0.05 .

\section{Results}

CT (computerised tomographic) imaging from 27 cases of OSA was evaluated retrospectively, alongside 9 normal controls. The mean age of the obstructive sleep apnoea cases was $38.67 \pm 11.12$, whilst that of the control group was $36.33 \pm 17.46$. The cross sectional measurements of the right and left nasal valve areas, the right and left middle nasal passage areas, the choanal area, the retrouvulal area and the retrolingual areas and the corresponding $\mathrm{p}$ values are indicated in Table 1.

Table 1. The mean \pm standard deviation (SD), the minimum-maximum and the $p$ values for the obstructive sleep apnoea and control groups of patients.

\begin{tabular}{llllc} 
& \multicolumn{2}{c}{ Obstructive sleep apnoea patients } & \multicolumn{2}{c}{ Control patients } \\
& \multicolumn{1}{c}{ Mean \pm SD } & Min-Max & Mean \pm SD & Min-Max \\
\hline Age & $38.67 \pm 11.12$ & $21.00-58.00$ & $36.33 \pm 17.46$ & $17.00-68.00$ \\
Right nasal valve area & $143.71 \pm 34,58$ & $80.01-222.16$ & $110.93 \pm 34,62$ & $55.79-187.97$ \\
Left nasal valve area & $137.25 \pm 39.50$ & $63.98-214.66$ & $120.28 \pm 28.39$ & $61.98-164.73$ \\
Right middle nasal passage & $185.27 \pm 97.72$ & $70.73-525.30$ & $166.89 \pm 60.45$ & $103.37-275.28$ \\
Left middle nasal passage & $170.11 \pm 49.08$ & $108.92-293.99$ & $150.70 \pm 40.76$ & $92.61-226.16$ \\
Choanal area & $515.80 \pm 87.63$ & $394.66-727.94$ & $417.15 \pm 119.08$ & $261.68-592.72$ \\
Retrouvulal area & $134.87 \pm 70.64$ & $32.37-278.90$ & $171.98 \pm 77.86$ & $96.63-335.49$ \\
Retrolingual area & $233.48 \pm 97.19$ & $55.64-457.89$ & $251.97 \pm 110.39$ & $123.66-398.11$ \\
\hline
\end{tabular}




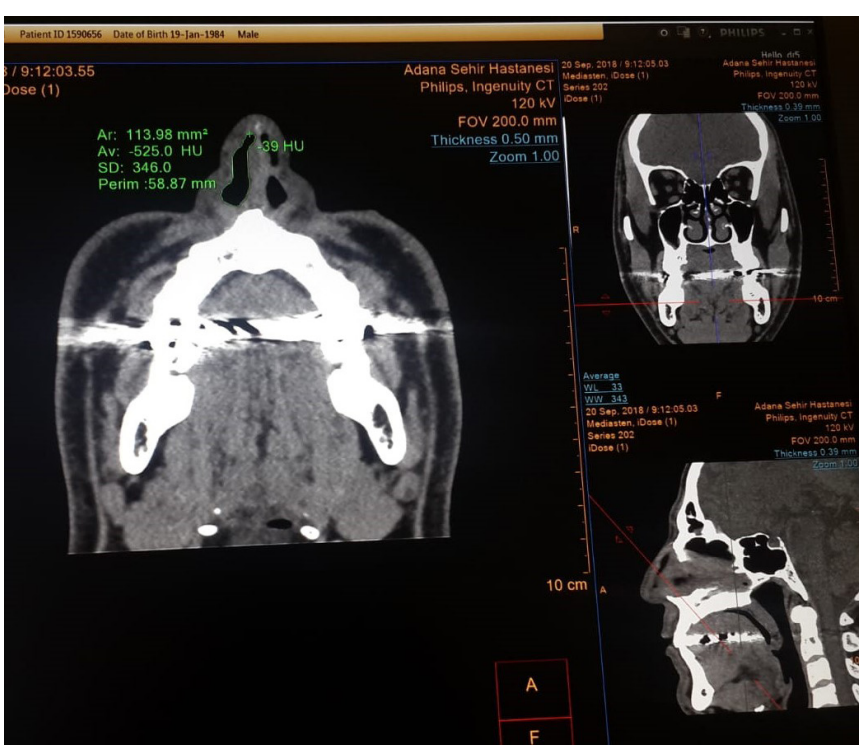

Figure 1. Cross sectional area of nasal valve.

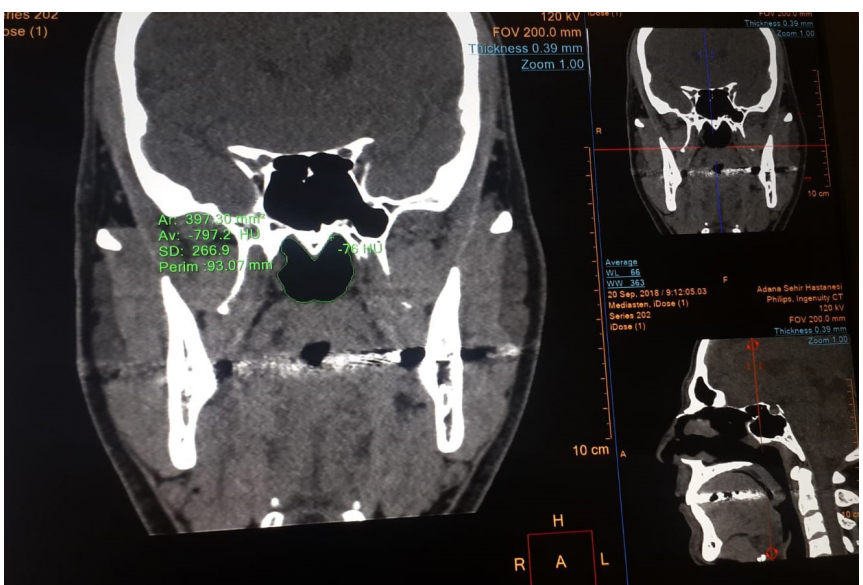

Figure 3. Cross sectional area of choanal region.

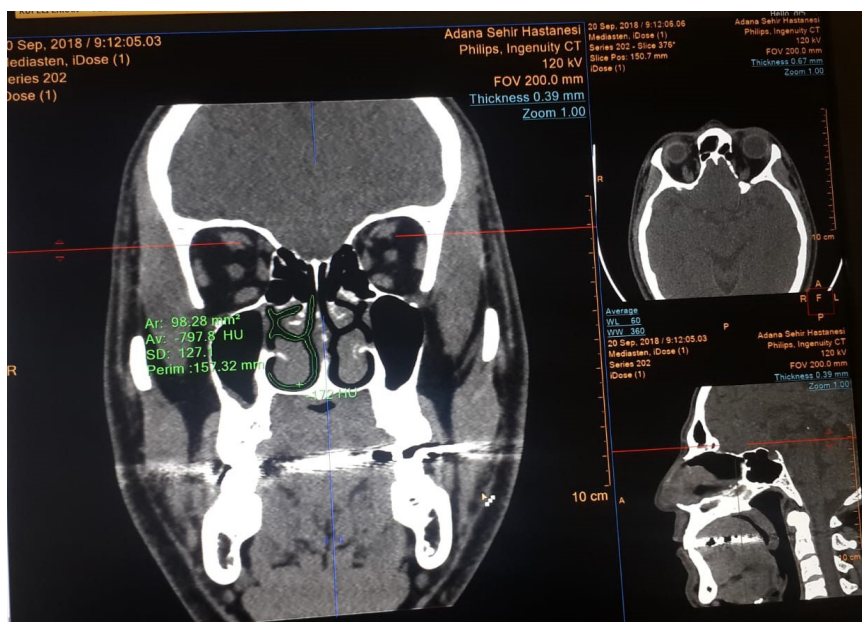

Figure 2. Cross sectional area of middle nasal region.

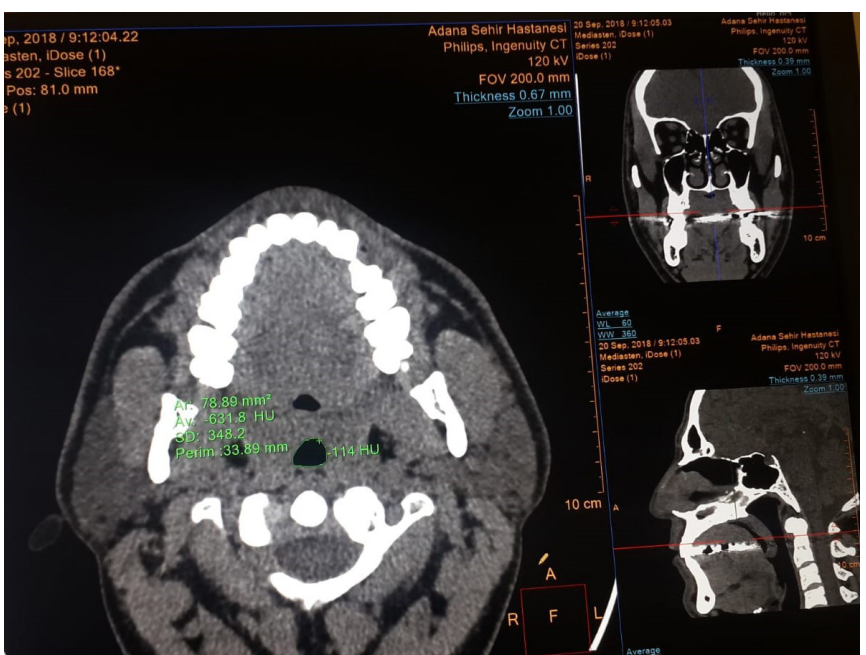

Figure 4. Cross sectional area of retro-uvulal region.

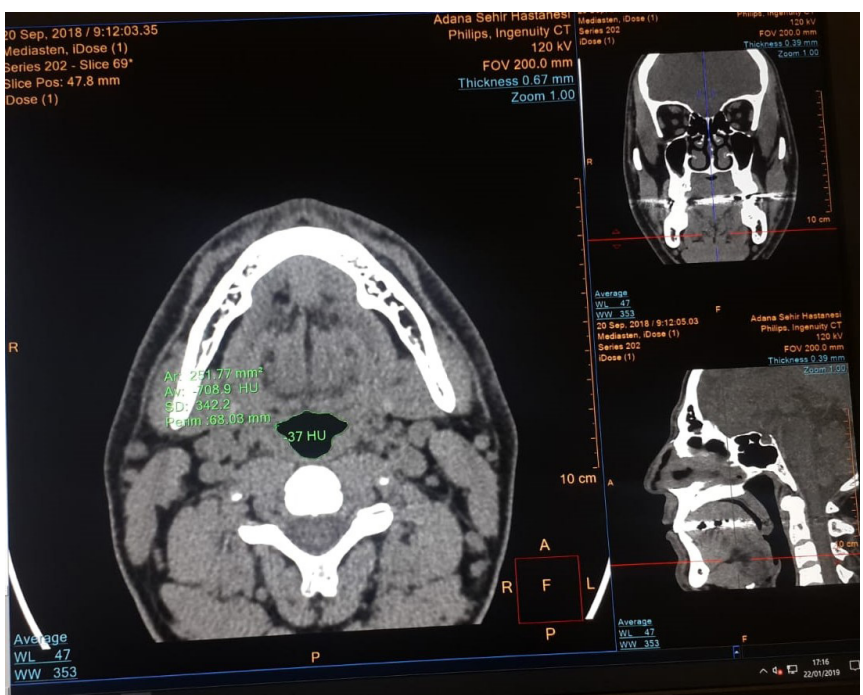

Figure 5. Cross sectional area of retrlingual region.

The means of the nasal valve and choanal cross sectional areas differed from the normal control means at the level of statistical significance $(\mathrm{p}=0.019$ and $\mathrm{p}=0.012$, respectively). See Table 1.

An increase in the value obtained for the right nasal valve of just 1 unit increases the risk of disease by 1.033 times. (Figure 6) A 1-unit increase in choanal area value increases the risk of disease by 1.012-fold (Figure 7).

\section{Discussion}

OSA is both widely prevalent and conveys a heavy social 


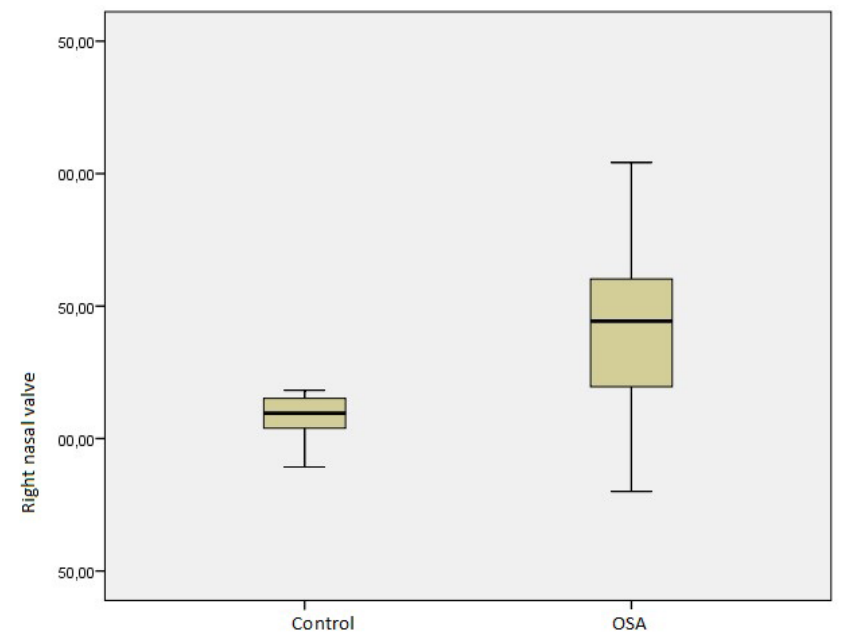

Figure 6 . The right nasal valve area of the control and obstructive sleep apnoea (OSA) patients.

burden. A number of different operations can now be performed to rectify anatomical anomalies and it is a matter of great importance to be able to identify where exactly the anomalies lie in order that surgical treatment can be most effectively directed. Currently, there is a multitude of technologies besides CT that can be used to investigate the narrowed areas within the upper airway, yet there remains much debate about what the benefits and drawbacks of each method are (14).

Our literature search did not reveal any previous study aiming to compare cross sectional airway measurements done in OSA cases by means of CT. This is, to the best of our knowledge, the first study to systematically analyse the dimensions of the nasal valve area, the middle nasal passage area, the choanal area, the retrouvulal and the retrolingual regions.

Blakley published research examining how the nose functions in OSA. The study compared air resistance in the nasal cavity between 53 known cases of OSA and 37 healthy controls. Whilst showing that OSA is indeed associated with greater airflow resistance in the nose, the degree to which this occurred did not have a correlation with other markers for the severity of the disorder. Thus, the researchers concluded, resistance to nasal airflow, whilst part of OSA, is not a key determinant of the severity of OSA (15).

Leitzen et al. performed a cross-sectional analysis of a cohort of 100 individuals, $59 \%$ of whom were deemed to

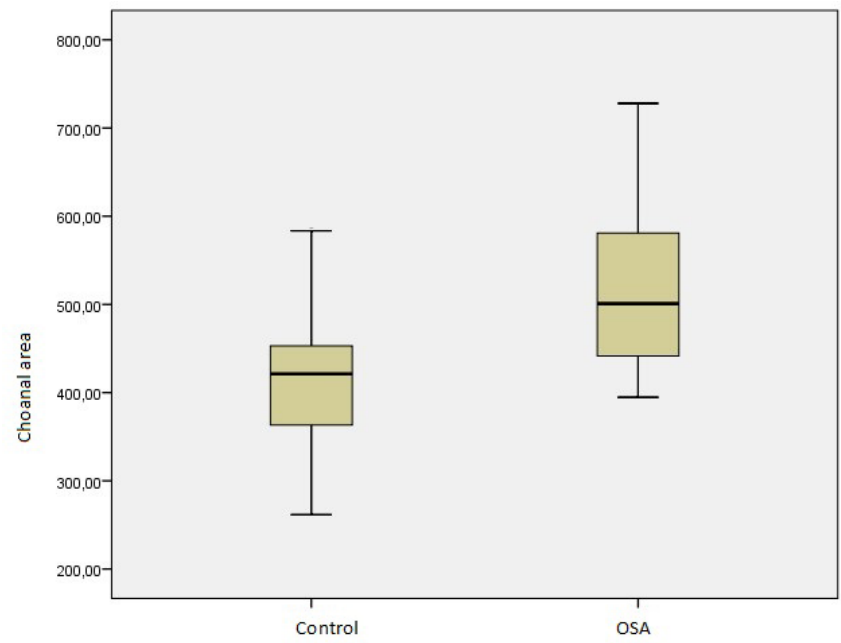

Figure 7. The choanal area of the control and the obstructive sleep apnoea (OSA) patients.

have OSA. They performed objective measurements of the anatomical features of the nose, but observed no correlation of significance with the degree of illness as quantified by polysomnography. The research supported the thesis that the degree of subjectively reported blockage of the nose correlates with obstruction within the nasal cavity as assessed by the objective anatomical measurements (16).

The most frequently observed zone for obstruction to occur within the nose in OSA is the retropalatal zone. Marquez et al. examined 14 cases, concluding that the airway in the retropalatal zone was more narrow and prone to collapse than in the retroglossal zone (17). For the specific ethnic group of Chinese (East Asian) OSA sufferers, the key area to be narrowed in the airway was the retropalate, such that there was a correlation (inverse) between the respiratory disturbance index and the degree of constriction. Additionally, body weight could also act to alter how the retropalatal airway is constricted through pressure on the lateral walls (18).

Barkdull et al. conducted research that revealed specific anatomical characteristics of the retrolingual portion of the airway found in OSA cases. These characteristics are quantifiable on CT imaging of the upper airway. Notably, a severe degree of OSA (i.e. an AHI of 40 or above) correlates with a trend for the retrolingual portion of the airway to be below $4 \%$ of the total cross-sectional area defined by the cervicomandibular ring. For patients with severe OSA, the retrolingual airway is the key point at which the airway 
is narrowed and this necessitates careful measurement before contemplating surgical intervention (19).

The majority of clinicians perform CT on patients who are awake. Reduced cross-sectional area of the airway is found in proportion to degree of OSA severity. Dynamic CT imaging reveals that cases of mild or moderate OSA do not have such marked reductions in airway cross-sectional area as the more severe cases. CT has a number of benefits: the airway can be visualised in its entirety; precise measurements are facilitated with the potential for $3 \mathrm{~d}$ assessment and calculation of cross sectional area; and the procedure is non-invasive. Correspondingly, the drawbacks include the high relative expense, radiation exposure hazards, brief recording interval and the fact that it is not possible to encompass the whole of the pharyngeal portion of the airway in a single plane (20).

Chousangsuntorn et al. state that CT imaging with a patient asleep and experiencing OSA showed obstruction occurring at multiple levels more clearly than in awake subjects. Values of the respiratory disturbance index that were markedly elevated in any case had a clear association with the airway becoming totally occluded and with concentric-type obstructed airways during episodes of OSA. The way that measurements obtained from CT for the upper airway (such as length, cross-sectional areas and the volume) relate to respiratory parameters awaits future clarification (21).

Buchanan's research established that the following parameters differ in OSA individuals compared to healthy individuals: airways are narrower; the airway as a whole has a

\section{References}

1. Young T, Palta M, Dempsey J, et al. The occurrence of sleep-disordered breathing among middle-aged adults. N Engl J Med 1993;328:1230-5.

2. Punjabi NM. The epidemiology of adult obstructive sleep apnea. Proc Am Thorac Soc 2008;5:136-43.

3. Bixler EO, Vgontzas AN, Lin HM, et al. Prevalence of sleepdisordered breathing in women: effects of gender. Am J Respir Crit Care Med 2001;163:608-13.

4. Bearpark H, Elliott L, Grunstein R, et al. Snoring and sleep apnea. A population study in Australian men. Am J Respir Crit Care Med 1995;151:1459-65.

5. Duran J, Esnaola S, Rubio R, Iztueta A. Obstructive sleep apneahypopnea and related clinical features in a population-based sample of subjects aged 30 to 70 yr. Am J Respir Crit Care Med 2001;163:685-9. Ip MS, Lam B, Lauder IJ, et al. A community study of sleepdisordered breathing in middle-aged Chinese men in Hong Kong. Chest 2001;119:62-9.

6. Ip MS, Lam B, Tang LC, et al. A community study of sleepdisordered breathing in middle-aged Chinese women in Hong Kong: prevalence and lower volume on average; mean areas and volumes are less; and the airway is longer overall. The findings of this study support the notion that how the patient is positioned during scanning (e.g. upright or supine) has an effect on the dimensions of the upper airway when viewed antero-posteriorly. Before CT can be relied on for screening OSA cases in the upright position, a more robust (prospective) methodology will be needed for confirmation of which parameters can be safely employed in assement (width, overall airway volume, average cross-sectional area, or length of airway) (22).

In the present study, a statistically significant narrowing of the nasal valve on the right and the cross-sectional area of the choanae was observed for the OSA cases. Such narrowing may reflect that those who have it will be prone to OSA. However, we did not observe statistically significant narrowing of the mid-nasal passage area, the retrouvulal or the retrolingual portions of the airway in OSA cases compared to controls. This negative finding may reflect either the study being under-powered due to sample size or be related to how the CT subjects were positioned.

\section{Conclusion}

The nasal valve and the choanal area cross-sectional narrowing may be related to a susceptibility to develop obstructive sleep apnoea. In obstructive sleep apnoea syndrome, further studies with larger patient populations are called for to analyse the upper airway cross-sectional area parameters needed to use for screening potential OSA cases.

gender differences. Chest 2004;125:127-34

7. Kim J, In K, Kim J, et al. Prevalence of sleep-disordered breathing in middle-aged Korean men and women. Am J Respir Crit Care Med 2004;170:1108-13.

8. Udwadia ZF, Doshi AV, Lonkar SG, Singh CI. Prevalence of sleepdisordered breathing and sleep apnea in middle-aged urban Indian men. Am J Respir Crit Care Med 2004;169:168-73.

9. Asha'ari ZA, Hasmoni MH, Rahman JA, Yusof RA, Ahmad RARL. The association between sleep apnea and young adults with hypertension. Laryngoscope 2012;122(10):2337-2342.

10. Sakat MS, Sütbeyaz Y, Yüceler Z, Kantarcı M, Kılıç K, Kurt S. Cephalometric measurements with multislice computed tomography in patients with obstructive sleep apnea. J Craniofac Surg 2016;27(1):82-6.

11. Bloching MB. Disorders of the nasal valve area. GMS Curr Top Otorhinolaryngol Head Neck Surg 2007;6:Doc07.

12. Sher AE. Upper airway surgery for obstructive sleep apnea. New Jersey: Wiley; 2006. 365p. 
13. Olszewska E, Rutkowska J, Czajkowska A, Rogowski M. Selected surgical managements in snoring and obstructive sleep apnea patients. Med Sci Monit 2012;18(1):13-18.

14. Hong SN, Won TB, Kim JW, Lee CH. Upper airway evaluation in patients with obstructive sleep apnea. Sleep Med Res 2016;7(1):1-9.

15. Blakley BW, Mahowald MW. Nasal resistance and sleep apnea. Laryngoscope 1987;97(6):752-4.

16. Leitzen KP, Brietzke SE, Lindsay RW. Correlation between nasal anatomy and obfective obstructive sleep apnea severity. Otolaryngol Head Neck Surg. 2014;150(2):325-31.

17. Marques M, Genta PR, Azarbarzin A et al. Correlation between nasal anatomy and objective obstructive sleep apnea severity. Respir Physiol Neurobiol. 2018;258:98-103.

18. Chen NH, Li KDDS, Li SY, Wong CR. Airway assesment by volumetric computed tomography in snorers and subjects with obstructed sleep ap- nea in a Far-East Asian population. Laryngoscope 2002;112(4):721-726.

19. Barkdull GC, Kohl CA, Patel M, Davidson TM. Computed tomography imaging of patients with obstructive sleep apnea. Laryngoscope 2008;118(8):1486-1492.

20. Seung-No Hong, Tae-Bin Won, Jeong-Whun Kim. Upper airway evaluation in patients with obstructive sleep apnea. Sleep Medicine Research 2016;7(1):1-9.

21. Chousangsuntorn K, Bhongmakapat T, Apirakkittikul N et al. Computed Tomography Characterization and Comparison With Polysomnography for Obstructive Sleep Apnea Evaluation. J Oral Maxillofac Surg 2018;76:854-872.

22. Buchanan A, Cohen R, Looney S et al. Cone-beam CT analysis of patients with obstructive sleep apnea compared to normal controls. Imaging Science in Dentistry 2016; 46: 9-16.

This is an open access article distributed under the terms of the Creative Commons Attribution-NonCommercial-NoDerivs 3.0 Unported (CC BY- NC-ND3.0) Licence (http://creativecommons.org/licenses/by-nc-nd/3.0/) which permits unrestricted noncommercial use, distribution, and reproduc- tion in any medium, provided the original work is properly cited.

Please cite this article as: D. Y. S., G. F. F., Morphological Analysis Of Obstructive Sleep Apnoea Patients Using Computed Tomography. ENT Updates 2019;9(1): 5-10 